\title{
Utdanning og legemiddelbruk
}

\section{Sammendrag \\ Bakgrunn. Mange studier har vist at lav sosioøkonomisk posisjon er assosiert med dårlig helse. Vi ønsket å undersøke hvorvidt bruk av reseptbelagte legemid- ler generelt og innenfor utvalgte lege- middelgrupper varierer med utdanning.}

Materiale og metode. For 645023 menn og kvinner født i perioden 1960-69 og bosatt i Norge i 2001 koblet vi data om utdanning fra folke- og boligtellingen i 2001 med data om legemiddelutleveringer fra Reseptregisteret i perioden 2004-09. Utleveringsfrekvensen av legemidler totalt ble sammenliknet på seks utdanningsnivåer. For 42 utvalgte legemiddelgrupper beregnet vi den relative risikoen assosiert med korttidsutdanning ( $\leq 10$ år) sammenliknet med langtidsutdanning (> 10 år) for å få utlevert minst ett legemiddel i perioden.

Resultater. Det var en dose-responssammenheng mellom utdanning og antall legemiddelutleveringer. Grunnskoleutdannede hentet i gjennomsnitt ut reseptbelagte legemidler rundt tre ganger oftere enn forskerutdannede. Gjennomsnittlig relativ risiko for legemiddelutlevering ved korttidsutdanning ( $\leq 10$ år) sammenliknet med langtidsutdanning ( $>10$ år) for de 42 utvalgte legemiddelgruppene var 1,29 for menn og 1,31 for kvinner

Fortolkning. Gitt at utlevering av legemidler er et uttrykk for helsetilstand, støtter våre funn tidligere studier som har vist at det er en sosial ulikhet $i$ helse i den voksne befolkningen.
Vidar Hjellvik

vidar.hjellvik@fhi.no

Milada Mahic

Aage Tverdal

Avdeling for legemiddelepidemiologi

Nasjonalt folkehelseinstitutt

Det er et kjent fenomen at helsetilstanden varierer med sosioøkonomisk posisjon. I en studie der man sammenliknet utdanningsrelaterte forskjeller i sykelighet, dødelighet og selvopplevd generell helse i 11 vesteuropeiske land, var Norge det landet som hadde størst forskjeller i selvopplevd helse mellom utdanningsnivå (1). Folkehelseinstituttet har gitt ut to rapporter om sosial ulikhet i helse basert på forskjellige mål for helse $(2,3)$, og $i$ en rapport fra Helsedirektoratet (4) ser man spesielt på sammenhengen mellom utdanning og helse. Denne sammenhengen er kompleks og kan gå begge veier. Videre kan bakenforliggende årsaker - som for eksempel dårlige oppvekstvilkår - resultere i både dårlig helse og kort utdanning. Rapporten konkluderer likevel med at «hva utdanningen bringer med seg, gir altså et vesentlig bidrag til prosessene som genererer helse og helseulikheter utover i det voksne livsløpet» (4, s. 125). En måte å måle helsetilstanden på kan være ved legemiddelbruk. I denne artikkelen ser vi på sammenhengen mellom utdanning og utleverte legemidler blant middelaldrende norske kvinner og menn.

\section{Materiale og metode}

Vi inkluderte alle menn og kvinner født i perioden 1960-69 som var registrert med utdanning i folke- og boligtellingen i 2001 (Fob2001) og som var i live og ikke hadde emigrert per 31. desember 2009 (Folkeregisteret). Utdanningsnivået i Fob2001 er klassifisert i henhold til Norsk standard for utdanningsgruppering 2000 (5) fra «ingen utdanning og førskoleutdanning» (kode lik 0) til «forskerutdanning» (kode lik 8). Vi slo sammen de tre laveste nivåene (grunnskole) samt nivå 4 og 5 og brukte seks kategorier (tab 1). Nivå 5 - påbygging til videregående ble slått sammen med nivå 4 - videregående, avsluttende - siden det var relativt få personer på nivå 5 og siden nivå 5 ikke nødvendigvis medfører høyere utdanning enn nivå 4 (mange går direkte fra 4 til 6). Ved sammenlikning av kort- og langtidsutdanning definerte vi korttidsutdanning som videregående grunnutdanning eller mindre ( $\leq 10$ år) og langtidsutdanning som videregående avsluttende utdanning eller mer (> 10 år). Denne inndelingen (cutoff) gir relativt lik størrelse på gruppene. Av 680305 individer (49\% kvinner) født i perioden 1960-69 som var med i Fob2001, døde 4827 før 1. januar 2010 (38\% kvinner) og 15892 emigrerte (41\% kvinner). For resten av populasjonen manglet det informasjon om utdanning for 14563 personer (47\% kvinner). Den gjenværende populasjonen besto av 645023 personer, fordelt på 223582 korttidsutdannede (53\% kvinner) og 421441 langtidsutdannede (47\% kvinner).

Reseptregisteret ble opprettet i 2004 og inneholder informasjon på individnivå om legemidler utlevert fra apotek. Alle legemidler som er registrert i Norge er gruppert etter ATC-systemet (Anatomical Therapeutic Chemical classification system (6)), der legemidler inndeles i grupper på fem nivåer. På nivå 1 fordeles legemidlene på 14 anatomiske hovedgrupper (f.eks. gruppe $\mathrm{N}$ - nervesystemet) og nivå 2 er terapeutiske eller farmakologiske undergrupper (f.eks. gruppe N02 smertestillende midler). ATC-koder for legemidler brukt i Norge er gitt på Felleskatalogens gule sider. Reseptregisteret inneholder bl.a. følgende informasjon om hver utlevering: pasientløpenummer, ATC-kode, utleveringsdato, mengde utlevert i definerte døgndoser (DDD (6)) og antall pakninger, apotekets utsalgspris, type resept samt egenandel der dette er relevant (for refusjonsresepter under blåreseptforskriften). Hvis et individ får utlevert flere ulike legemidler samtidig, blir dette registrert som én utlevering per legemiddel. Vi vet ikke hvorvidt legemidler som blir utlevert fra apotek blir brukt eller ikke, men vi mener allikevel at utleverte legemidler kan være et godt mål på legemiddelbruk.

Data om død og emigrasjon var tilgjengelig via kobling med Folkeregisteret.

\section{Hovedbudskap}

- Personer med lav utdanning fikk utlevert mer legemidler enn dem med høy utdanning

- Kjønnsforskjellen var liten i de fleste legemiddelgruppene

- Felles for de fleste av legemiddelgruppene som ble utlevert oftere til langtidsutdannede, er at de ikke brukes til behandling av kroniske lidelser 
Tabell 1 Fordeling på utdanningskategori og kjønn. I folke- og boligtellingen i 2001 (FoB2001) var utdanning kodet i henhold til Norsk standard for utdanningsgruppering 2000 (5). I våre analyser brukte vi både inndelingen i seks kategorier og i to grupper

\begin{tabular}{|c|c|c|c|c|}
\hline Utdanningskategori (NUS2000) & N (\% kvinner) & Utdanningsnivå (kategorier) & Utdanningsnivå (grupper) & N (\% kvinner) \\
\hline 0 Ingen utdanning og førskole & $951(63)$ & 1 Grunnskole & 1 Korttidsutdanning & $223582(53)$ \\
\hline 1 Barneskole & $1682(62)$ & & & \\
\hline 2 Ungdomsskole & 52535 (45) & & & \\
\hline 3 Videregående, grunnutdanning & $168414(55)$ & 2 Videregående I & & \\
\hline 4 Videregående, avsluttende & $200640(42)$ & 3 Videregående II & 2 Langtidsutdanning & $421441(47)$ \\
\hline 5 Påbygging til videregående & $24030(41)$ & & & \\
\hline 6 Universitet/høyskole, lavere nivå & $151343(58)$ & 4 Universitet/høyskole I & & \\
\hline 7 Universitet/høyskole, høyere nivå & 42035 (40) & 5 Universitet/høyskole II & & \\
\hline 8 Forskerutdanning & 3393 (33) & 6 Forskerutdanning & & \\
\hline 9 Uoppgitt/data mangler & $14563(47)$ & & Totalt & 645023 (49) \\
\hline
\end{tabular}

Først sammenliknet vi ulike mål for total legemiddelbruk i de seks utdanningskategoriene gitt i tabell 1:

- andel individer som ikke fikk utlevert noen legemidler i perioden 2004-09

- antall ulike legemidler utlevert i perioden

- antall utleveringer

- antall definerte døgndoser

- kostnad i kroner for individ (hvite resepter og egenandel på blåresepter) og stat

Før frikort ble sendt ut automatisk kunne summen av egenandelene registrert i Reseptregisteret for en gitt person i løpet av et kalenderår overstige egenandelstaket hvis personen ikke skaffet seg frikort når denne grensen var nådd. I så fall kunne vedkommende få tilbakebetalt det overskytende beløpet fra HELFO. Vi antok derfor at reell egenandel for en gitt person et gitt kalenderår var lik egenandelstaket hvis summen av egenandelene i Reseptregisteret oversteg denne grensen. Gjennomsnittlig beløp for blåresepter dekket av staten i de ulike utdanningskategoriene ble så beregnet som gjennomsnittlig utsalgspris minus gjennomsnittlig antatt reell egenandel. Egenandelstaket i perioden steg jevnt fra 1550 kroner i 2004 til 1780 kroner i 2009.

Videre sammenliknet vi utlevering av legemidler i utvalgte legemiddelgrupper blant kort- og langtidsutdannede (definert i tabell 1). For denne analysen valgte vi ut de 40 legemiddelgruppene på 2. nivå i ATCsystemet der flest individer fikk minst én utlevering i perioden 2004-09, og gruppe L03 (immunstimulanter) og L04 (immunsuppressiver) som har få brukere, men høy omsetning i kroner. For hver av de 42 gruppene beregnet vi for menn og kvinner den relative risikoen assosiert med korttidsutdanning i forhold til langtidsutdanning for å få minst én utlevering av et legemiddel innen gruppen i denne perioden.

Koblingen mellom Reseptregisteret, Folkeregisteret og folke- og boligtellingen i 2001 ble godkjent av Datatilsynet og Regional etisk komité (REK), og dataene ble brukt $i$ avidentifisert form.

\section{Resultater}

Totalt legemiddelbruk i seks utdanningskategorier

Alle våre mål på mengde utleverte legemidler viste en klar sammenheng med utdanning: Jo høyere utdanning, desto lavere mengde utlevert (fig 1).

\section{Prosentandel som} ikke har hentet ut resepter i 2004-09

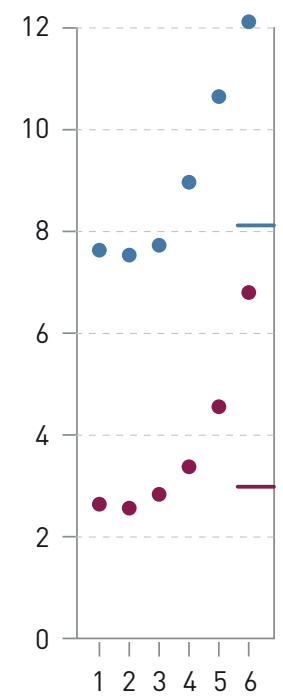

Kvinner
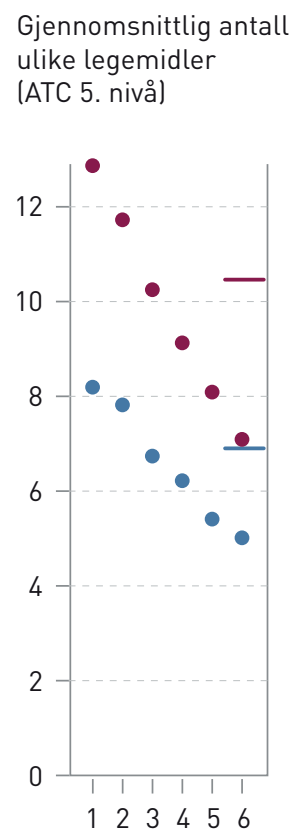
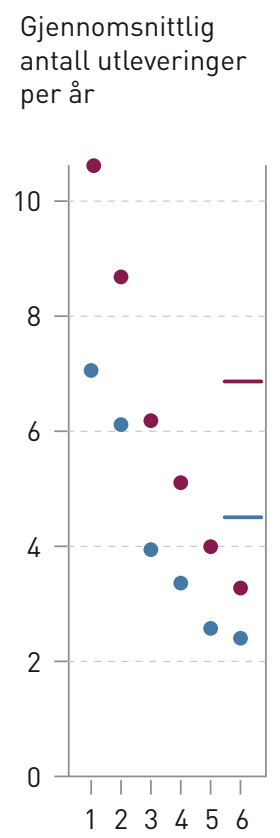
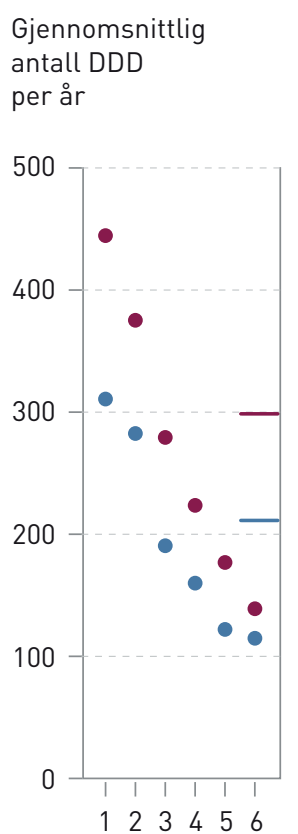
Gjennomsnittlig
kostnad i kroner
per år

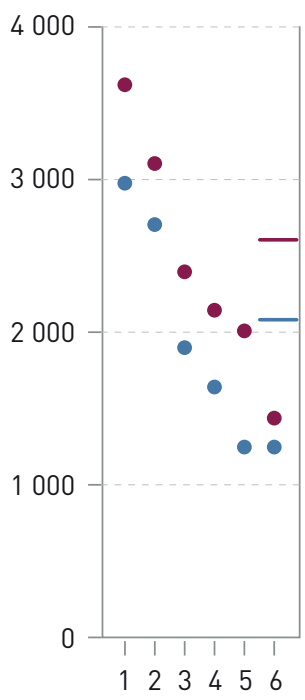

Utdanningsnivå

Figur 1 Ulike mål på utlevering av reseptbelagte legemidler i perioden 2004-09 for personer født 1960-69 etter utdanningsnivå (definert i tab 1). Prosentandel/gjennomsnitt for hele den kvinnelige og mannlige populasjonen er vist til høyre i hvert panel. De to første panelene viser tall for hele seksårsperioden. 


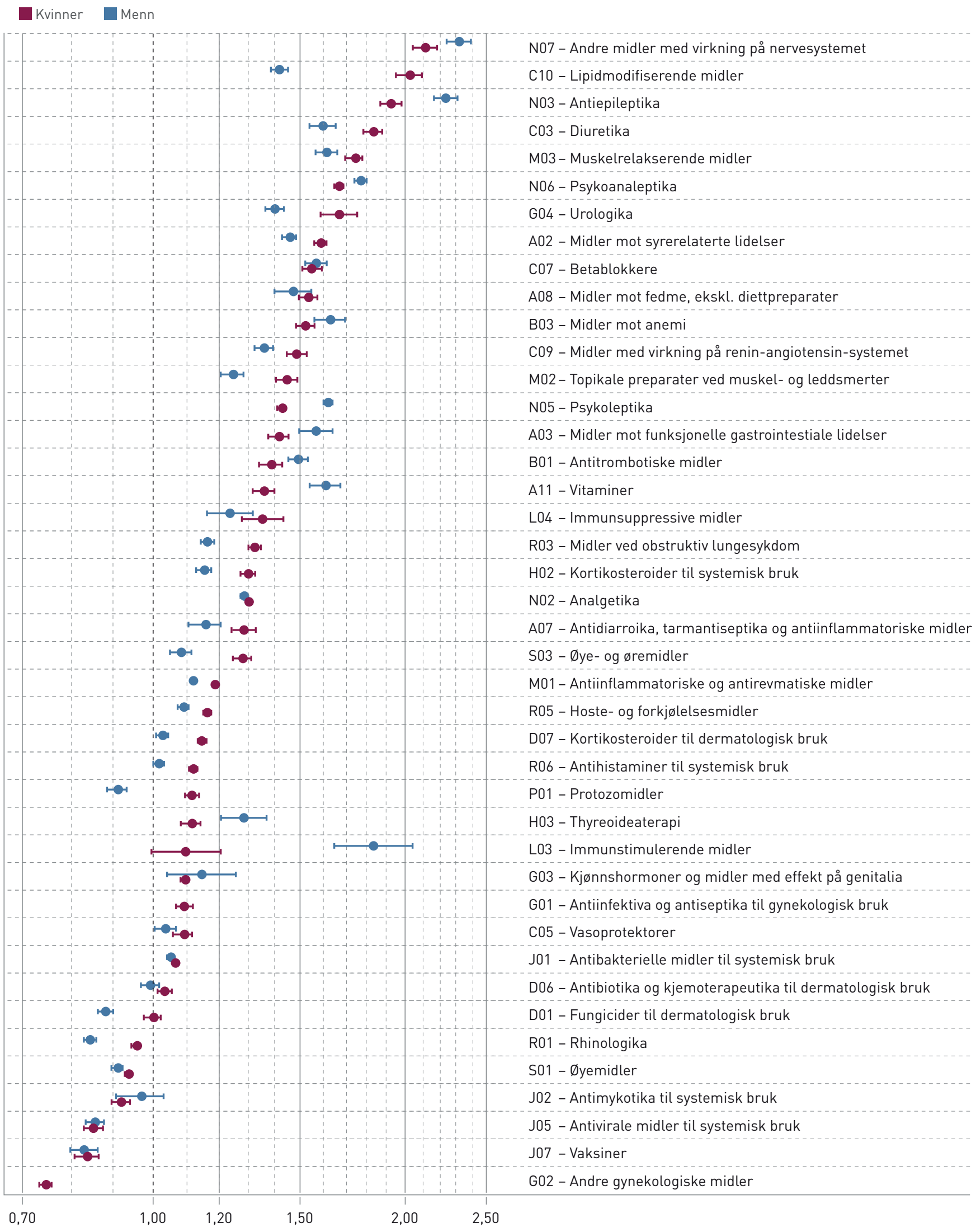

Relativ risiko

$$
\begin{gathered}
\text { Lengre utdanning, } \\
\text { mer legemidler } \\
\text { mer legemidler }
\end{gathered}
$$

Figur 2 Relativ risiko assosiert med lav utdanning ( 10 år) for personer født 1960-69 for minst én utlevering i løpet av 2004-09 i hver av de 40 mest brukte legemiddelgruppene på 2. nivå i ATC-systemet (målt i antall individer i den aktuelle aldersgruppen som fikk minst én utlevering) samt L03 og L04. Sortert etter relativ risiko for kvinner. G01 og G02 er ikke vist for menn på grunn av få utleveringer. Horisontale linjer indikerer 95 \% konfidensintervall. Grå stiplede vertikale linjer viser intervall i relativ risiko på 0,1 


\begin{tabular}{|c|c|c|c|c|c|c|c|}
\hline & Utdanningsnivå & Grunnskole & $\begin{array}{l}\text { Videre- } \\
\text { gående I }\end{array}$ & $\begin{array}{l}\text { Videre- } \\
\text { gående II }\end{array}$ & $\begin{array}{l}\text { Universitet/ } \\
\text { høyskole I }\end{array}$ & $\begin{array}{l}\text { Universitet/ } \\
\text { høyskole II }\end{array}$ & $\begin{array}{l}\text { Forsker- } \\
\text { utdanning }\end{array}$ \\
\hline \multirow{3}{*}{ Menn } & Sum betalt av individet & 6669 & 5528 & 3308 & 2808 & 2237 & 2083 \\
\hline & Sum dekket av staten & 11183 & 10595 & 8025 & 7000 & 5276 & 5385 \\
\hline & Totalt & 17852 & 16123 & 11333 & 9808 & 7513 & 7469 \\
\hline \multirow{3}{*}{ Kvinner } & Sum betalt av individet & 8194 & 6596 & 5213 & 4668 & 4575 & 3381 \\
\hline & Sum dekket av staten & 13419 & 11976 & 9088 & 8104 & 7392 & 5265 \\
\hline & Totalt & 21613 & 18572 & 14301 & 12772 & 11967 & 8646 \\
\hline
\end{tabular}

$8 \%$ av mennene og $3 \%$ av kvinnene fikk ikke utlevert reseptbelagte legemidler i studieperioden (fig 1, panel 1 fra venstre). Andelen var relativt konstant til og med for utdanningskategori 3 og deretter klart økende. Forskjellen mellom laveste og høyeste utdanningskategori var mellom 4 og 5 prosentpoeng for begge kjønn (fig 1).

Antall ulike utleverte legemidler på 5. nivå i ATC-systemet avtok jevnt med økende utdanningsnivå (fig 1, panel 2). Grunnskoleutdannede fikk utlevert omtrent tre ganger så mye legemidler som forskerutdannede målt $\mathrm{i}$ antall utleveringer og sum DDD. Utdanningsgradienten var sterkere for kvinner enn for menn (fig 1, panel 3-4). Målt i kroner fikk grunnskoleutdannede utlevert omtrent 2,5 ganger så mye legemidler som forskerutdannede, både for kvinner og menn (fig 1, panel 5 og tab 2).

\section{Bruk av utvalgte legemidler \\ $i$ to utdanningsgrupper}

Figur 2 viser relativ risiko for utlevering av minst ett legemiddel innen hver av de undersøkte legemiddelgruppene blant korttidsutdannede $(\leq 10$ år) sammenliknet med langtidsutdannede ( $>10$ år). Øverst ligger legemidler fra ATC-gruppe N07 - andre midler med virkning på nervesystemet som ble utlevert til 3,9\% av mennene og $4,1 \%$ av kvinnene. Relativ risiko var litt over 2 for både menn og kvinner, som betyr at sannsynligheten for å få utlevert minst ett legemiddel fra ATC-gruppe N07 var litt over dobbelt så stor for kortidsutdannede som for langtidsutdannede. Det hyppigst utleverte legemidlet i denne gruppen var vareniklin som brukes til behandling av nikotinavhengighet. ATC-gruppe N07 ble for kvinner tett etterfulgt av C10 - lipidmodifiserende behandling - som er dominert av statiner (C10AA) (98\% av dem som fikk utlevert ett eller flere legemidler i gruppe C10 fikk minst ett statin). Videre analyser viste ingen utdanningsrelaterte tendensforskjeller mellom dem som hentet ut simvastatin, atorvastatin eller andre statiner (data ikke vist). Nederst i figur 2 ligger legemidler fra ATCgruppe G02 (andre gynekologiske midler), J07 (vaksiner) og J05 (antivirale midler). Det betyr i denne sammenheng at sannsynligheten for å få utlevert minst ett legemid- del var høyere for de langtidsutdannede enn for de kortidsutdannede. De hyppigst utleverte legemidlene i gruppen G02 var lokale antikonseptiva.

Legemidler fra ATC-gruppe J01 - antibakterielle midler til systemisk bruk - var de legemidlene som ble utlevert til størst andel av populasjonen: $59,7 \%$ av mennene og $71,2 \%$ av kvinnene fikk utlevert minst ett antibakterielt middel. For denne legemiddelgruppen var det beskjeden eller ingen forskjell i sannsynligheten for utlevering mellom de to utdanningsgruppene.

Legemidler i ATC-gruppe L04 - immunsuppresive midler - hadde høyest omsetning i kroner, men ble kun utlevert til ca. $1 \%$ av populasjonen. Legemidlene som dominerer denne gruppen hva gjelder kostnader er TNF- $\alpha$-hemmere (L04AB). Med tanke på utdanning tilsvarte utleveringsmønsteret $\mathrm{i}$ gruppe L04 andre legemiddelgrupper, og mer detaljerte analyser av Humira og Enbrel, (selvadministrerte TNF- $\alpha$-hemmere), viste ingen spesielle avvik i forhold til hele gruppe L04 (data ikke vist).

Kjønnsforskjellen i relativ risiko var i de fleste legemiddelgrupper relativt liten. Den største kjønnsforskjellen ble observert gruppe L03 - immunstimulerende midler hvor utdanningskontrasten var klart størst hos menn. Analyser på legemiddelnivå viste at hele utdanningsforskjellen for menn $\mathrm{i}$ gruppen kunne forklares av L03AB10 og L03AB11 (peginterferon- $\alpha-2 \mathrm{a}$ og peginterferon- $\alpha-2 b$, midler mot kronisk hepatitt $B$ og C). Omtrent fire ganger så mange korttidsutdannede som langtidsutdannede menn fikk minst én utlevering av peginterferon- $\alpha$ (data ikke vist). Blant kvinner var utleveringsraten ca. tre ganger så høy blant korttidsutdannede. Kjønnsforskjellen var også stor i ATC-gruppe C10 - lipidmodifiserende midler - der utdanningskontrasten var størst for kvinner. I ATC-gruppe P01 - protozomidler - var sannsynligheten for utlevering hos menn størst blant langtidsutdannede, mens den hos kvinner var størst blant korttidsutdannede.

En analyse tilsvarende den i figur 2, men med seks utdanningskategorier, viste en gradvis økende risiko med avtakende utdanning for nesten alle legemiddelgrupper i øvre halvdel av figur 2 (data ikke vist).

\section{Diskusjon}

I den grad utlevering av legemidler gir uttrykk for en helsetilstand, uttrykker våre funn dårligere helse blant individer med kortere utdanning. Imidlertid er det andre faktorer enn helsen som kan påvirke hvorvidt et individ får utlevert et legemiddel eller ikke. For eksempel er høyt blodtrykk og høyt kolesterol i hovedsak tilstander der forskrivers vurdering av behandlingsbehov vil spille en sentral rolle. Hvorvidt en forskrivers vurdering påvirkes av pasientens utdanningsnivå, vet vi ikke. En norsk studie viste at sannsynligheten for å få utlevert et statin varierte med utdanningsnivå, men variasjonen forsvant når det ble tatt hensyn til kolesterolnivået (7). Forskjeller i kolesterolnivå forklarte altså sammenhengen mellom utdanning og statinutlevering. Eller med andre ord: forskjeller i sannsynligheten for statinutlevering etter utdanning gjenspeilte forskjeller i helsetilstanden etter utdanning. En svensk studie som undersøkte sammenhengen mellom utdanning og 22 ulike legemiddelkategorier fant at $\mathrm{i}$ de fleste kategoriene samsvarte sammenhengen mellom utdanning og legemiddelbruk med sammenhengen mellom utdanning og prevalens av korresponderende sykdom funnet $\mathrm{i}$ andre studier (8). Et ytterligere argument for at befolkningens sykdomsbyrde avtar med økt utdanning, er at levealderen øker med økt utdanning. Av dem i den aktuelle aldersgruppen som deltok på FoB2001, døde $1,3 \%$ av dem med grunnskole og $0,3 \%$ av dem med forskerutdanning i løpet av 2009.

Like fullt kan utdanning virke inn på holdningen til legemiddelbruk. Det kan godt tenkes at de med lang utdanning er mer skeptiske til - og kanskje har mer realistiske forestillinger om - hva moderne medisin (inkludert legemidler) gir av helseeffekter. Det kan også tenkes at korttidsutdannede oppsøker lege oftere enn langtidsutdannede fordi kunnskapsnivået er lavere, for eksempel om virussykdommer.

Sammenhengen mellom sosioøkonomi, herunder utdanning, og helse er kompleks. De fleste modeller setter opp et hierarki med sosial struktur, sosial posisjon, miljø og livsstil som determinanter for helse (9). Sammenhengen mellom utdanningsnivå og røyking er dokumentert (10), og støttes også av 
våre funn, da legemidler mot nikotinavhengighet utgjør en stor del av N07, som var legemiddelgruppen med høyest relativ risiko i vår studie. Tilsvarende betraktning kan gjøres for utdanningsgradienten for midler ved obstruktiv lungesykdom. Heller ikke legemiddelgruppene med lavest relativ risiko, G02 (andre gynekologiske midler) og J07 (vaksiner), gis for behandling av sykdom. Siden de fleste vaksiner ikke er registrert $i$ Reseptregisteret, kan vårt resultat ikke relateres til vaksinering generelt. Felles for de aller fleste av legemiddelgruppene som ble utlevert oftere til langtidsutdannede (relativ risiko lavere enn 1) er at de ikke brukes til behandling av kroniske lidelser, og at de i den forstand er mindre assosiert med dårlig helse. For noen legemidler er det ikke åpenbart at utdanningsforskjellen i forskrivning av legemidler kan tilskrives miljø eller livsstil, for eksempel midler mot anemi (B03). Vi presiserer at det dreier seg om sammenhenger og at vi ikke kan si noe om årsak.

Noen modeller går videre og inkluderer sosiale konsekvenser av helse (11). På denne måten blir helse både en eksponering for sosial posisjon og et resultat (utfall) av sosial posisjon. For å teste helse som determinant for sosial posisjon, bør tilsvarende analyser som vi har gjort gjøres på yngre mennesker der forskrivningshistorien ligger før endelig utdanning i tid.

Våre analyser gir ikke grunnlag for å si at det er sammenheng mellom legemiddelkostnader, forskrivers vurdering av behandlingsbehov og pasientens utdanningsnivå. TNF- $\alpha$ hemmere har de siste årene toppet omsetningsstatistikken i Norge. De representerer den nyeste og dyreste behandlingen for en del lidelser med overaktivt immunsystem, som f.eks. revmatoid artritt, inflammatorisk tarmsykdom og psoriasis. Forbruksmønsteret sett mot utdanning for TNF- $\alpha$-hemmere tilsvarte andre legemiddelgrupper. Analysene av ulike statiner viste også samme utdanningsgradient for simvastatin som for atorvastatin, som er noe dyrere. Selv om det her er behov for flere og mer detaljerte analyser, tyder dette på at høyt utdannende legemiddelbrukere generelt ikke får utlevert bedre og nyere legemidler enn lavt utdannede. For TNF- $\alpha$-hemmere er det også viktig å ha i bakhodet at lidelsene som blir behandlet med disse ofte vil kunne føre til funksjonshemninger som kan påvirke utdanningsforløpet.

Selv om utdanningsnivået til pasienten kan tenkes å påvirke både legens og pasientens vurdering av behovet for legemidler, kan dette neppe forklare hele sammenhengen mellom utdanningsnivå og utlevering av legemidler. Vår konklusjon er derfor at data fra Reseptregisteret støtter tidligere studier som har vist at det er en sosial ulikhet i helse i den voksne befolkningen, og at kort utdanning er assosiert med høyere utgifter til legemidler både for individet og staten.

\section{Vidar Hjellvik (f. 1961)}

er dr.scient. i statistikk og seniorforsker ved Avdeling for legemiddelepidemiologi, Nasjonalt folkehelseinstitutt.

Forfatter har fylt ut ICMJE-skjemaet og oppgir ingen interessekonflikter.

\section{Milada Mahic (f. 1977)}

er cand.pharm., ph.d. og seniorrådgiver ved Avdeling for legemiddelepidemiologi, Nasjonalt folkehelseinstitutt.

Forfatter har fylt ut ICMJE-skjemaet og oppgir ingen interessekonflikter.

\section{Aage Tverdal (f. 1944)}

er dr.philos. i statistikk og seniorforsker ved Avdeling for legemiddelepidemiologi, Nasjonalt folkehelseinstitutt.

Forfatter har fylt ut ICMJE-skjemaet og oppgir ingen interessekonflikter.
Litteratur

1. Mackenbach JP, Kunst AE, Cavelaars AE et a Socioeconomic inequalities in morbidity and mortality in western Europe. Lancet 1997: 349: 1655-9.

2. Zahl P-H, Rognerud M, Strand BH et al. Bedre helse - større forskjeller. Rapport 2003: 1. Oslo: Nasjonalt folkehelseinstitutt, 2003.

3. Ness $\emptyset$. Rognerud M Strand BH, red. Sosial ulikhet i helse. En faktarapport Rapport 2007: 1. Oslo: Nasjonalt folkehelseinstitutt, 2007.

4. Elstad JI. Utdanning og helseulikheter. Problemstillinger og forskningsfunn. Oslo: Helsedirektoratet, 2008

5. Statistisk sentralbyrå. Norsk standard for utdanningsgruppering. Oslo/Kongsvinger: Statistisk sentralbyrå, 2012

6. WHO Collaborating Centre for Drug Statistics Methodology. Guidelines for ATC classification and DDD assignment. Oslo: WHO Collaborating Centre for Drug Statistics Methodology, Nasjonalt folkehelseinstitutt, 2010

7. Selmer R, Sakshaug S, Skurtveit S et al. Statin treatment in a cohort of 20212 men and women in Norway according to cardiovascular risk factors and level of education. Br J Clin Pharmacol 2009; 67: $355-62$

8. Weitoft GR Rosén M, Ericsson 0 et al. Education and drug use in Sweden-a nationwide registerbased study. Pharmacoepidemiol Drug Saf 2008; 17: $1020-8$

9. Graham H. Unequal lives: health and socioeconomic inequalities. Berkshire: Open University Press, 2007

10. Grøholt E-K, Grøtvedt L, Hånes H et al, red. Helsetilstanden i Norge. Rapport 2010: 2. Oslo: Nasjonalt folkehelseinstitutt, 2010.

11. Mackenbach JP, van de Mheen H, Stronks K. A prospective cohort study investigating the expla nation of socio-economic inequalities in health in The Netherlands. Soc Sci Med 1994; 38: 299-308.

Mottatt 28.11. 2011, første revisjon innsendt 20.3 2012, godkjent 28.6. 2012. Medisinsk redaktør Merete Kile Holtermann. 